\title{
Temporal Filtering Properties of Midbrain Neurons in an Electric Fish: Implications for the Function of Dendritic Spines
}

\author{
Gary J. Rose and Susan J. Call \\ Department of Biology, University of Utah, Salt Lake City, Utah 84112
}

Electrosensory neurons in the torus semicircularis (midbrain) of the weakly electric fish Eigenmannia vary considerably in their dendritic structure and responses to modulations of the amplitude of electric organ discharges. We investigated possible relations between these properties by recording intracellularly and labeling individual neurons while modulating stimulus amplitude over rates of approximately 2-20 Hz. Morphologically distinct cell types generally differed in their responses to these stimuli. The amplitude envelope of the stimulus was nicely reflected in fluctuations of the membrane potential of heavily spined neurons. The amplitude of these stimulus-related depolarizations decreased markedly as the stimulus modulation rate was increased. For aspiny or sparsely spined neurons, however, the amplitude of stimulus-related depolarizations either increased or remained constant over this range of modulation rates. In these cells, the amplitude envelope of the stimulus was not well represented in the membrane potential. Instead, fast EPSPs were observed that varied in number over time in accordance with the amplitude envelope of the stimulus. Aspiny neurons in the tectum also coded the amplitude envelope of stimuli with poor fidelity. The amplitude of stimulus-related depolarizations, however, decreased as the rate of modulation of stimulus amplitude was increased, consistent with the notion that tectal neurons receive afferent input from the spiny toral neurons.

Spiny nourons appear, therefore, to act as low-pass filters of temporal information in sensory signals. Aspiny cells, however, code high temporal frequencies. These data support the hypothesis that dendritic spines contribute to the low-pass filtering of inputs to neurons.

IKey words: neuroethology, jamming avoidance response, temporal processing, dendritic spines, torus semicircularis, evolution, intracellular recording, sensory processing]

Temporal variation in the amplitude of signals received by sensory receptors is important in acoustic and electric communication (Rose, 1986). Modulations in the amplitude of emitted signals also may provide potentially useful environmental information. For example, bats may detect the fluttering of an insect's wings, in part, by sensing modulations of the amplitude of an echo of its sonar vocalization (Schnitzler et al., 1984).

\footnotetext{
Received Apr. 8, 1992; revised Aug. 21, 1992; accepted Sept. 24, 1992.

We thank Jim Canfield for reviewing the manuscript, and Nathan Etter and Phillip Kinser for providing technical help. This project was supported by Grant BNS-8901601 from the National Science Foundation and a grant from the Sloan Foundation.

Correspondence should be addressed to Gary J. Rose at the above address. Copyright (C) 1993 Society for Neuroscience $0270-6474 / 93 / 131178-12 \$ 05.00 / 0$
}

Similarly, electric fish characterize their environment, that is, electrolocate objects, by sensing modulations in the amplitude and phase of periodic discharges of their electric organ (Heiligenberg, 1973; Bastian, 1986a; Rose and Heiligenberg, 1986) using electroreceptors distributed over their body surface (Bullock, 1982).

The electrolocation abilities of the weakly electric fish Eigenmannia can be impaired (jammed) by the discharges of another fish (Matsubara and Heiligenberg, 1978). Such interference results in fluctuations in the amplitude and phase of signals received by electroreceptors. To minimize jamming, Eigenmannia raises or lowers its frequency of electric organ discharges (EODs) if the jamming signal is lower or higher in frequency, respectively, thereby increasing the magnitude of the frequency difference (Df), or "beat rate" between the two signals (see Heiligenberg, 1989, 1991, for reviews). Beat rates of approximately 3-8 Hz are most detrimental to the fish's electrolocation abilities, and, correspondingly, elicit largest jamming avoidance responses (JARs) (Bullock et al., 1972; Heiligenberg et al., 1978; Partridge et al., 1981; Bastian and Yuthas, 1984).

As a neural correlate of this behavior, one class of neurons in the dorsal torus semicircularis (midbrain) responds best, that is, is tuned, to particular modulation rates. Most neurons are tuned to beat rates of approximately $2-6 \mathrm{~Hz}$ (Partridge et al., 1981). Primary afferents, however, act as high-pass filters up to modulation rates of at least $64 \mathrm{~Hz}$ (Bastian, 1981a). Similar transformations in the representation of amplitude modulations in the PNS and CNS have been shown in the auditory systems of crickets (Schildberger, 1984), anuran amphibians (Rose and Capranica, 1983, 1985; Walkowiak, 1984), birds (Hose and Langner, 1988), and mammals (Schreiner and Urbas, 1986, 1988).

The mechanisms underlying these transformations are presently unclear. Electrosensory afferents to toral neurons [from the electrosensory lateral line lobe (ELL)] code the rate of amplitude modulation in their periodicity of firing, but show little or no selectivity in their responses to beat rates that maximally elicit the JAR (Bastian, 1981b, 1986a; Partridge et al., 1981; Shumway, 1989); most neurons respond best to beat rates of 16 $\mathrm{Hz}$ or greater, whereas JARs are maximal at beat rates of approximately 3-8 Hz and virtually absent at $20 \mathrm{~Hz}$ (Bullock et al., 1972; Partridge et al., 1981). Although a small percentage of neurons in the ELL exhibit low-pass properties, relative to toral neurons only small decreases in response rate occur over this range of beat rates (Partridge et al., 1981; Shumway, 1989). Temporal selectivity over this range, therefore, results primarily from processes intrinsic to the torus or involving other afferents to toral neurons.

A "network" mechanism for this selectivity could involve a 
Afferents

Laminae

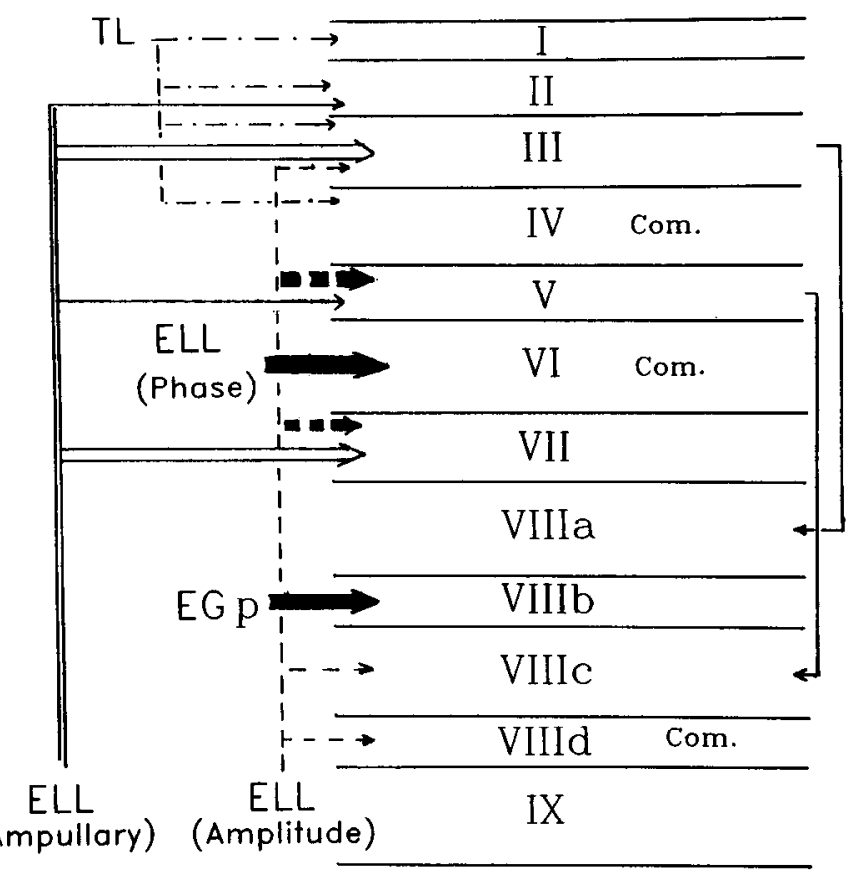

Figure 1. Laminar distribution of the major inputs to the dorsal division of the torus semicircularis. Ampullary afferents are sensitive to low-frequency electric signals. Tuberous afferents code the amplitude and phase of high-frequency electric signals, such as those generated by the animal's electric organ (Zakon, 1986). The width of the arrows denotes the strength of the projection. $E G p$, eminentia granularis, postcrior (electrosensory cerebellum); Com., commissural; $T L$, torus longitudinalis. The sparse projection from the descending nucleus of $\mathrm{V}$ to laminae $8 \mathrm{a}, 8 \mathrm{c}$, and 9 is not shown. The laminar distribution of tectal afferents is not known (Carr et al., 1981). Arrows on right denote local circuits. The electrosensory projection from the ELL is mainly contralateral.

direct, excitatory input and a delayed, inhibitory input. The reciprocal connections between the dorsal torus and the stratum album centrale layer of the tectum could represent such a circuit (Carr et al., 1981). A toral unit would respond best at the beat rate equal to the reciprocal of twice the delay between direct afferent excitation and the inhibition. According to this model, response minima should occur at multiples of this optimal rate. For example, a neuron tuned to a beat rate of $4 \mathrm{~Hz}$ should exhibit response minima at 8 and $16 \mathrm{~Hz}$.

An intriguing alternative hypothesis focuses on the role of dendritic spines in contributing to the pronounced low-pass temporal filtering properties of toral neurons. Spine stems can be as small as approximately $50 \mathrm{~nm}$ in diameter and $4 \mu \mathrm{m}$ in length (Peters and Kaiserman-Abramof, 1970; Peters et al., 1991); the actual conducting core of the stem is likely to be even smaller. Considerations such as these have led to theoretical suggestions that the axial resistance of spines may be quite high (for review, see Rall and Segev, 1987), and that low-pass filtering of inputs might result (Koch and Poggio, 1983).

We have begun testing these ideas by intracellularly recording from and labeling neurons in the dorsal torus semicircularis of Eigenmannia. This region consists of 12 laminae (Fig. 1) and approximately 48 cell types (Carr et al., 1981; Carr and Maler, 1985, 1986). We present the responses of morphologically characterized toral neurons to stimulus beat rates of approximately
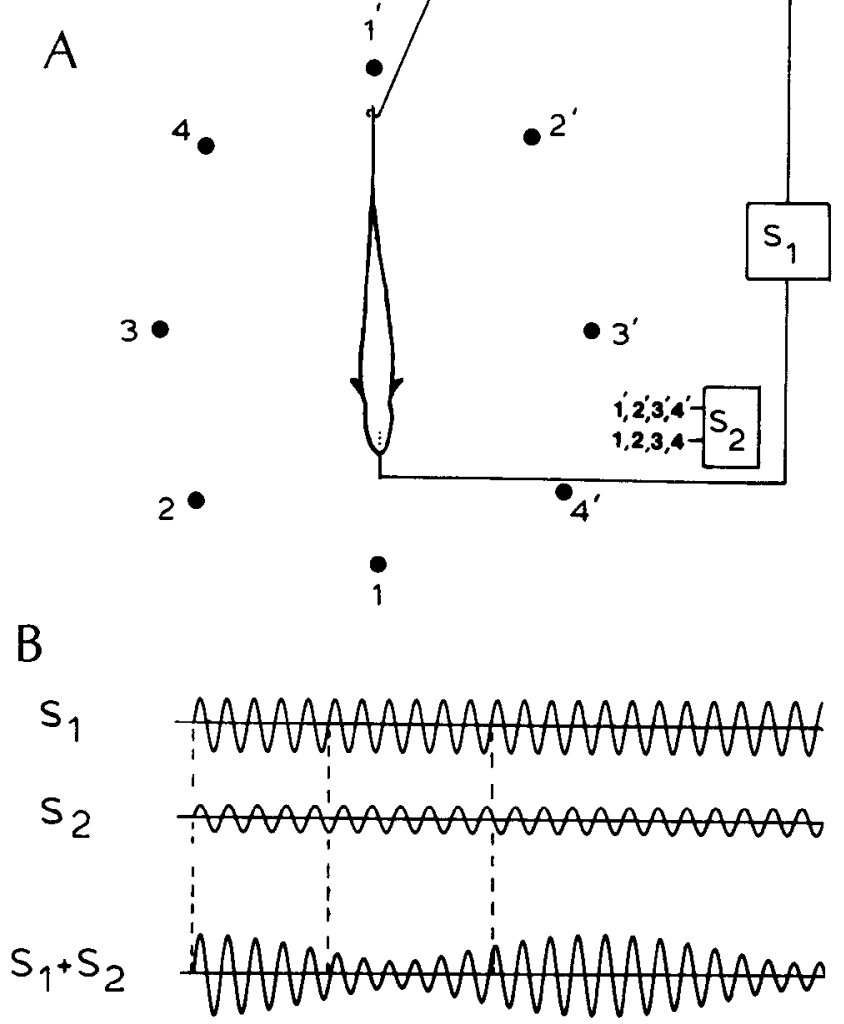

Figure 2. A, Diagram of the experimental setup used in this study. The fish's own EOD was silenced and replaced with a mimic $\left(S_{l}\right)$, delivered through electrodes in the mouth and at the tail $(1,1)$. A second signal $\left(S_{2}\right)$ either was presented through any of four pairs of carbon electrodes surrounding the fish or was added electronically to the $S_{I}$ and delivered through the mouth-tail electrodes. $B$, The summation of these two sinusoidal signals resulted in a "beating" waveform, wherein the amplitude and phase were modulated at a rate equal to the absolute magnitude of their Df.

$2-20 \mathrm{~Hz}$. There is extensive variation in spine density across neuron types in these layers, ranging from aspiny to heavily spined cells. Our findings are consistent with the hypothesis that dendritic spines contribute to the low-pass temporal filtering properties of neurons.

\section{Materials and Methods}

Experimental procedures were similar to those used in earlier intracellular investigations of the torus (Heiligenberg and Rose, 1985; Rose and Heiligenberg, 1985; Rose and Call, 1992). Fish of the genus Eigenmannia, 8-12 cm in length, were used. The electric organ discharge (EOD) (Bennett, 1971) was attenuated approximately 1000 -fold by intramuscular injection of Flaxedil $(4 \mu \mathrm{g} / \mathrm{gm}$ fish). The animal's own EOD was substituted by a sinusoidal mimic (S1) applied through an electrode in the mouth and an external electrode at the tail. With this stimulation arrangement, current penetrated the skin fairly perpendicularly and with the same polarity, as in the case of the normal EOD. The amplitude and frequency of this EOD-mimic were adjusted to approximate the amplitude and frequency of the EOD prior to administration of Flaxedil. A second sinusoidal signal (S2) was delivered either through the same pair of electrodes as was used for the EOD-mimic (S1) "identical" geometry), or through pairs of carbon rods surrounding the fish ("differential" geometry) (Fig. 2). This second signal is usually referred to as the "jamming" signal, sincc such signals may impair a fish's ability to electrolocate objects. A transverse jamming field is produced by delivering the signal (S2) through carbon electrode pair 3,3'; a longitudinal jamming field is produced by presenting the signal through carbon electrode pair 1,1'. Modulations in the amplitude and phase of 
the combined signal result from the constructive and destructive interference of the two signals [the EOD-mimic (S1) and the jamming signal (S2)] as they drift in and out of phase. In the "identical geometry" stimulus condition, all the electroreceptors "see" the same degree of modulation of the amplitude and phase of the electric signal. For the "differential geometry" condition, however, areas of the body surface that are orthogonal to the path of current flow (between a pair of carbon rods) will experience maximal modulations of signal amplitude and phase, whereas other areas will experience smaller modulations. In other words, presenting the jamming signal through the various pairs of carbon rods provides a spatially more discrete stimulus, whereas presenting the signal through the mouth-tail electrodes (identical geometry) gives rise to a spatially global stimulus.

The principal objective of this study was to relate the temporal filtering properties of toral neurons to their structure. No accounts will be made therefore, of differences in the responses of cells to variations in stimulus geometry. It is only important to note that we employed the stimulus geometry that best excited each neuron, and varied the beat rate by changing the frequency of the jamming signal. The frequency of the jamming signal was manually controlled by varying the voltage sent to the "external FM" input of a function generator. The "beat rate" was equal to the absolute magnitude of the frequency difference between the EOD-mimic (S1) and the jamming signal. To stimulate the ampullary system, low frequencies of the $S 1$ were employed, keeping the amplitude at the same value used for high frequencies.

Microelectrodes were manufactured by pulling capillary glass (alumina silicate, $1 \mathrm{~mm}$ o.d. $\times 0.75 \mathrm{~mm}$ i.d.) on a Brown-Flaming micropipette puller. The tips of these micropipettes were back-filled with a solution of $5 \%$ Lucifer yellow (VS) in distilled water, and the shanks were filled with either $1 \mathrm{~m} \mathrm{LiCl}$ or $\mathrm{LiAc}$; Lucifer yellow is in the form of a lithium salt. Since negative direct current $(2-4 \mathrm{nA})$ was used to iontophorese Lucifer yellow, lithium ions should not be delivered to the cell. These electrodes had resistances of approximately 125-200 $\mathrm{M} \Omega$.

Intracellular responses were recorded using an electrometer (767, World Precision Inst. Co.; input impedance $>10^{\prime \prime} \Omega$ ) and stored on videotape using a PCM adaptor; the rate of analog-to-digital conversion was 40 $\mathrm{kHz}$

While searching for neurons, the frequency of the jamming signal was $2-4 \mathrm{~Hz}$ above or below the frequency of the EOD-mimic and was presented with transverse geometry, that is, through electrodes 3 and $3^{\prime}$ (Fig. 2). Neurons were penetrated by applying one or a few brief positive current pulses to the micropipette. Penetration of a neuron was associated with a sudden negative drop in the potential recorded across the electrode. Changes in the level of polarization of the cell were made by varying the amount of negative current that was delivered through the electrode. Recordings generally were made at holding potentials just sufficiently negative to prevent postsynaptic potentials (PSPs) from triggering action potentials. Further hyperpolarization generally did not alter the amplitude of PSPs. The penetration site was identified as being most intensely labeled (see below). Only data acquired from soma recordings are presented in this article; dendritic recordings sometimes were made, but were less stable than soma recordings.

Fourier analysis of intracellular recordings was used to quantify the coding of the amplitude envelope of the stimulus by PSPs. The height of the peak in the power spectrum at the frequency equal to the beat rate was used as a measure of the amplitude of the stimulus-related PSPs. The relative power values reported in this article are based on PSPs recorded while employing the optimal stimulus geometry for each cell. The root-mean-square level of these PSPs also was calculated. The spectral method of analysis was robust against drifts in the baseline voltage that were unrelated to the stimulus. Each value was computed from at least $500 \mathrm{msec}$ of data; independent power measurements varied less than $\pm 1 \mathrm{~dB}$ for any particular stimulus condition. The beat rate during a recording was varied continuously (not in discrete steps) from approximately 2-20 Hz. PSPs could be observed, therefore, for all rates within this range. These records were scanned by eye and power measurements were made primarily at points of response maxima and minima.

At the end of an experiment the fish, deeply anesthetized by immersion in urethane $(2 \%)$, was perfused through the heart with a physiological saline-heparin solution, followed by a mixture of equal volumes of $8 \%$ paraformaldehyde and $0.2 \mathrm{M}$ phosphate buffer $(\mathrm{pH} 7.4)$. The brain was removed and fixed overnight in the paraformaldehyde solution, and $100 \mu \mathrm{m}$ sections were cut on a vibratome. To minimize the bleaching of Lucifer yellow when exposed to UV light, the antioxidant $5 \% n$-propyl gallate, in glycerol, was used as a mounting medium (Giloh and Sedat 1982).

Labeled neurons were drawn with the aid of a camera lucida attachment to an Olympus BHS microscope or their structure was stored digitally using a three-dimensional neuron tracing system (Eutectic Co.). Laminae could be distinguished by differences in autofluorescence; however, the exact laminar boundaries usually were difficult to discern These boundaries, therefore, are not shown in figures. Instead, the laminar distribution of a neuron's dendrites is described.

Spine density was computed by dividing the total number of spines counted for a neuron by the total dendritic length. Such computations were made directly, in cases where information concerning dendritic structure was acquired by viewing the dye-filled neuron, or by acquiring this information from camera lucida drawings and storing it in the computer. For neurons of the torus, spine densities computed using these two methods did not vary by more than $3 \%$; initial three-dimensional analyses have shown that these cells have rather planar dendritic fields, generally extending less than $50 \mu \mathrm{m}$ in the rostral-caudal dimension. In all cases, the computed spine density was an underestimate of the true density because spines that point upward or downward in the section may be obscured by the parent dendrite. For spines $3 \mu \mathrm{m}$ in length, approximately $5 \%$ of the spines will be blocked from view. This error is small and should not vary appreciably across neurons; therefore, corresponding "correction factors" were not applied to the spine density measurements reported in this article.

\section{Results}

\section{Background}

Primary afferents that innervate tuberous (sensitive to high frequencies) and ampullary (sensitive to low frequencies) electroreceptors terminate somatotopically in the electrosensory lateral line lobe (ELL) (Carr et al., 1982). Ampullary afferents project to the medial segment while tuberous afferents trifurcate and terminate in the other three segments (maps) of the ELL (Heiligenberg and Dye, 1982). Each segment contains "basilar" and "nonbasilar" pyramidal neurons, named with respect to the presence or absence, respectively, of a thick dendrite that extends ventrally from the soma (Maler, 1979; Maler et al., 1981). In the tuberous maps, basilar pyramidal neurons receive direct input from amplitude coding primary afferents and are excited by amplitude increases ("E" type). Nonbasilar pyramidal cells, however, receive input indirectly via inhibitory interneurons and consequently respond in a postinhibitory fashion to decreases in stimulus amplitude ("l" type) (Saunders and Bastian, 1984). These two types of pyramidal cells provide afferent input to the dorsal torus semicircularis (Fig. 1) (Maler et al., 1982).

We have classified labeled cells in accordance with Golgi types described by Carr and Maler (1985). With regard to the torus, we have focused our presentation on neurons that are located in laminae that receive afferent input from the tuberous segments of the ELL (Fig. 1). The physiology and anatomy of multipolar cells of the tectum also will be described; these neurons respond to beat stimuli. The various cell types found in these "focal" electrosensory areas are as follows.

Toral neurons: laminae 4 and 5. Neurons of these layers are excited by modulations of the amplitude of the EOD-mimic (Rose and Heiligenberg, 1985; Rose and Call, 1992). Five neuron types have been identified in lamina 4 from Golgi material (Carr and Maler, 1985). Of the 16 neurons labeled, 2 were type a (octopus), 12 were type $b$ (pyramidal/multipolar), and 2 were type c; types $d$ and e have not been filled. Type $c$ neurons are bilaminar, with apical dendrites in lamina 3 and a ventral dendrite terminating in lamina 7 . Limited recordings from type $c$ neurons suggest that they may receive both ampullary and tuberous input. Three neuron types have been identified in lamina 5. Of the 13 cells labeled, 4 were type a (pyramidal), 5 were type $\mathrm{b}$ (bilaminar), and 4 were type $\mathrm{c}$. 
A

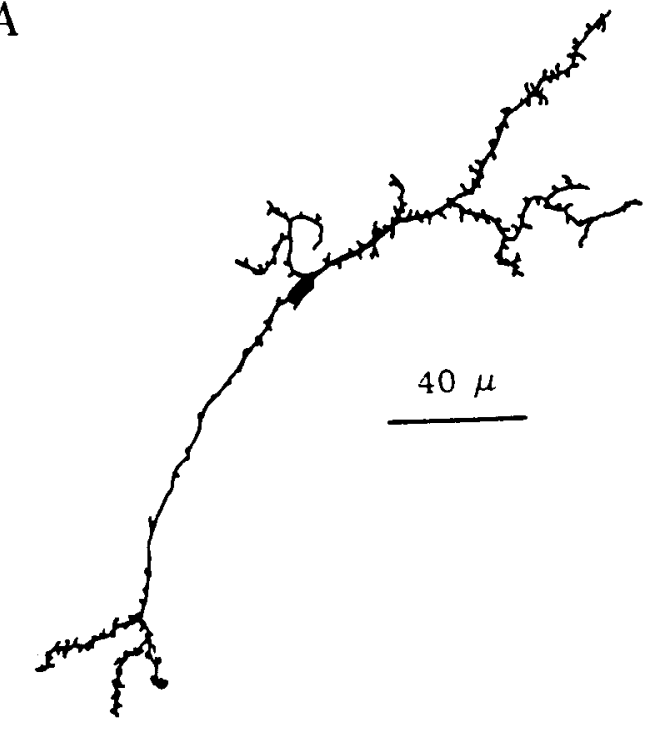

B

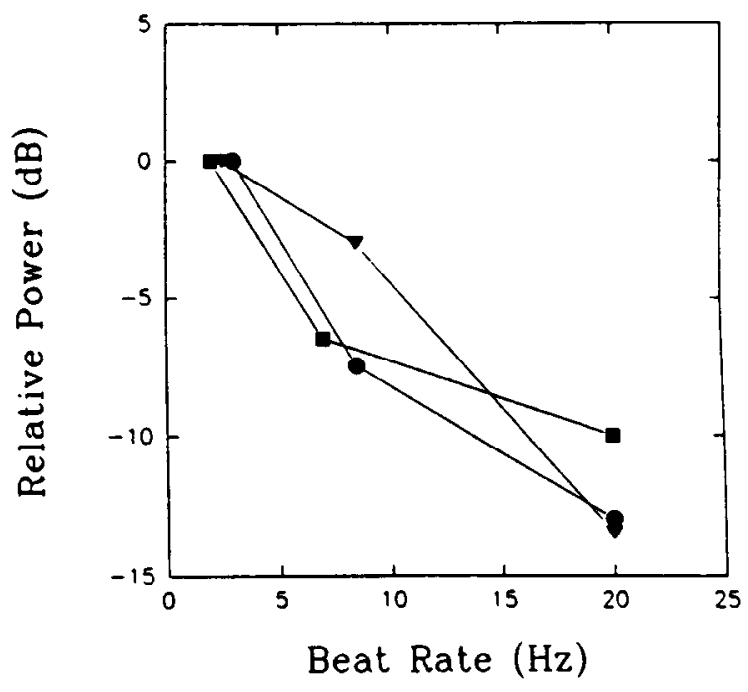

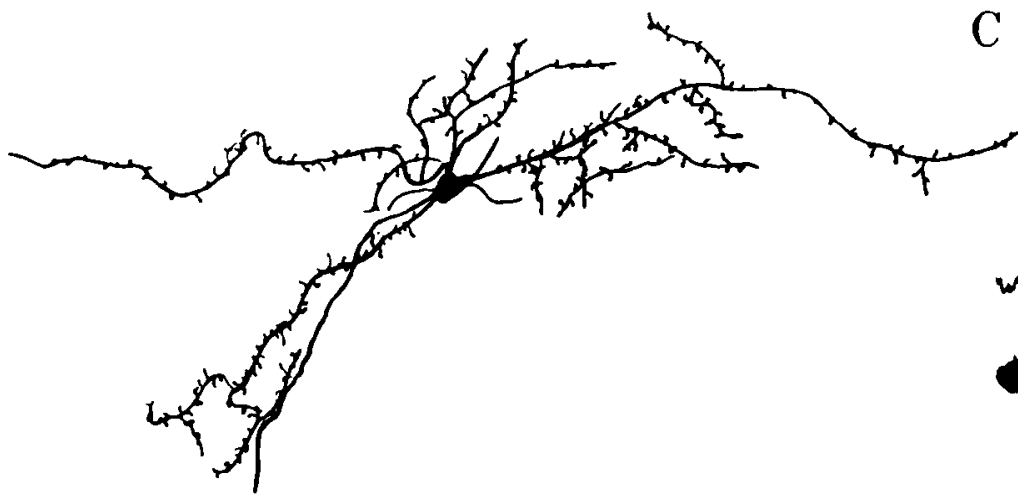

$\mathrm{C}$

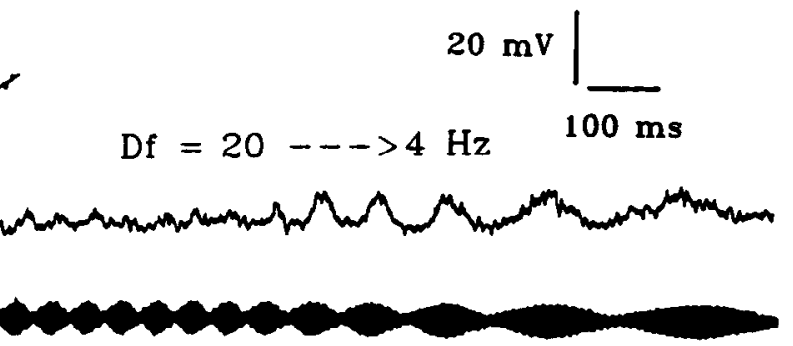

Figure 3. A, Type b neurons of lamina 5. B, Relative amplitude of stimulus-related PSPs as a function of the beat rate for three type b cells other than those in $A$. Circles, I-unit; squares, E-unit; triangles, E-I, excited for contralateral increases and ipsilateral decreases in stimulus amplitude. $C$, PSPs recorded intracellularly while the beat rate of the stimulus was changed from approximately $20 \mathrm{~Hz}$ to $4 \mathrm{~Hz}$. The beat rate is equal to the absolute magnitude of Df between the signal mimicking the EOD and the jamming signal. Quantification of the physiology from this unit is represented by triangles in $B$. Scale bar applies to both cells.

Lamina $8 c$. This layer consists of five cell types, only two of which were labeled. Two spiny pyramidal and two aspiny multipolar neurons were filled. The latter cell type has not been observed in Golgi material.

\section{Relations between physiology and anatomy}

Although presently there appears to be a continuum with respect to spine density, for the purposes of presentation we will partition neurons into three categories: heavily spined neurons $(>0.2$ spines $/ \mu \mathrm{m})$, neurons with intermediate spine density $(0.1-0.2$ spines $/ \mu \mathrm{m})$, and sparsely spined or aspiny neurons $(<0.1$ spines/ $\mu \mathrm{m})$.

Heavily spined neurons. Type b (bilaminar) neurons of lamina 5 (Fig. 3A) were consistently the most heavily spined neurons labeled. The spiny dendrites of these cells were distributed in laminae 5 and 7 . The ventral dendrite projected through zones of lamina 6 that were devoid of somas, that is, vertical neuropil columns. Spines were up to 4-5 $\mu \mathrm{m}$ long and had thin stems. Intracellularly recorded fluctuations of the membrane potential of type b neurons faithfully reflected the amplitude envelope of the beat pattern (Fig. 3C), and the magnitude of these PSPS decreased precipitously as the beat rate was increased (Fig. $3 B$ ); "low-pass" temporal selectivity functions for three type b cells are shown. Voltage fluctuations reflecting the amplitude envelope of the beat stimulus are not recorded while outside the cell or during intracellular recordings from afferents (Rose and Call, 1992) and therefore are not simply stimulus artifacts.

Pyramidal neurons of laminae 4 and 5 varied extensively across cells with respect to spine density, and in some cases were heavily spined (Fig. $4 A$ ). This particular case is a variant described by Carr and Maler (1985) that has a more multipolar dendritic organization than other pyramidal neurons. These "bilaminar" neurons of lamina 4 have parachute-like dorsal and ventral dendritic fields that extend into laminae 3 and 5 , respectively. The cell was excited by beat stimuli and by unmodulated, low-frequency signals, that is, received input from tuberous and ampullary systems, respectively (Fig. $4 D, C$ ). The periodic and sinusoidal nature of the low-frequency signal and amplitude envelope of the beating signal was reflected in the temporal fluctuations of the membrane potential. The amplitude of these stimulus-related PSPs was largest for beat rates of approximately $6 \mathrm{~Hz}$ and declined for lower or higher rates, that 

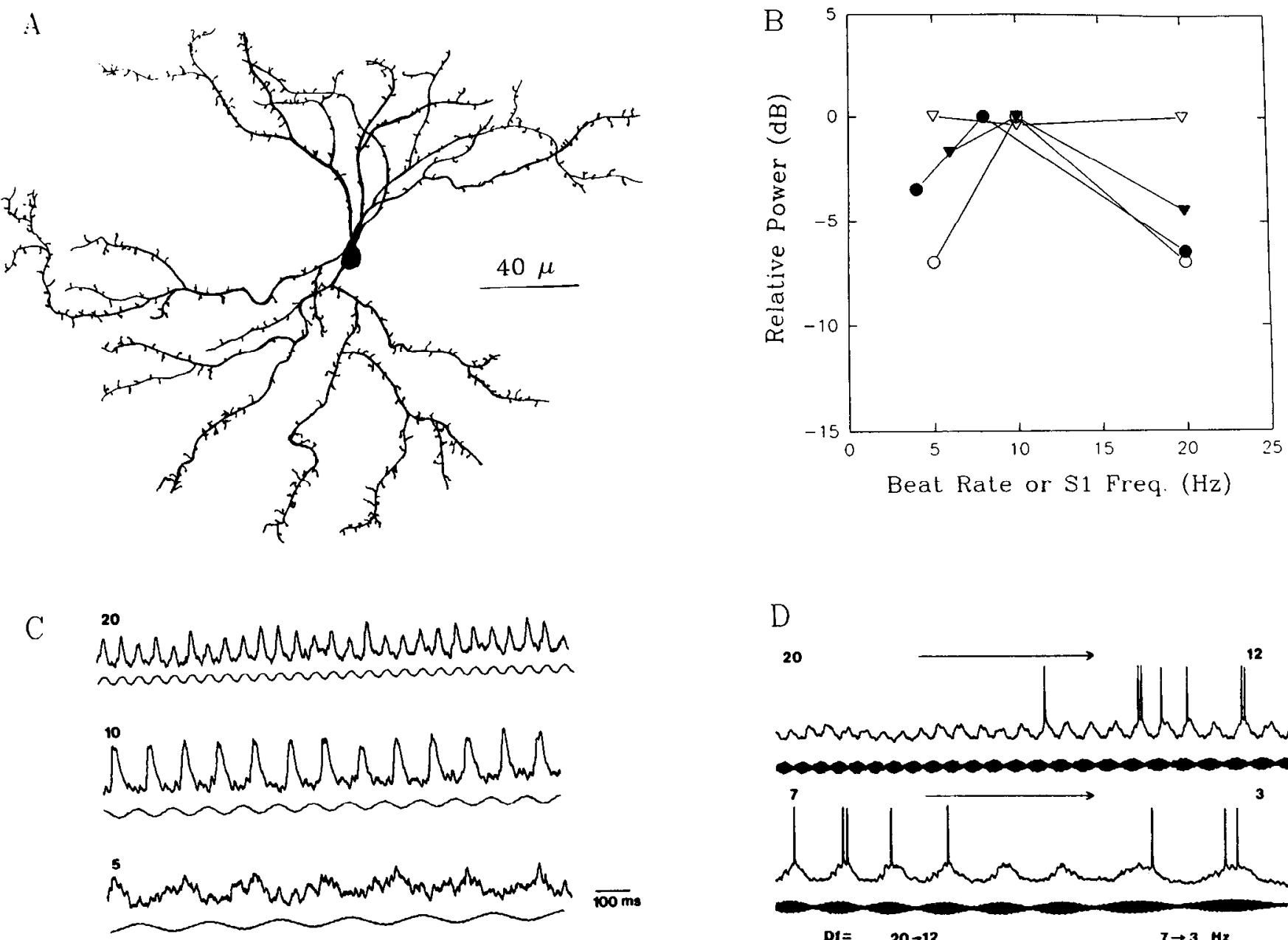

D

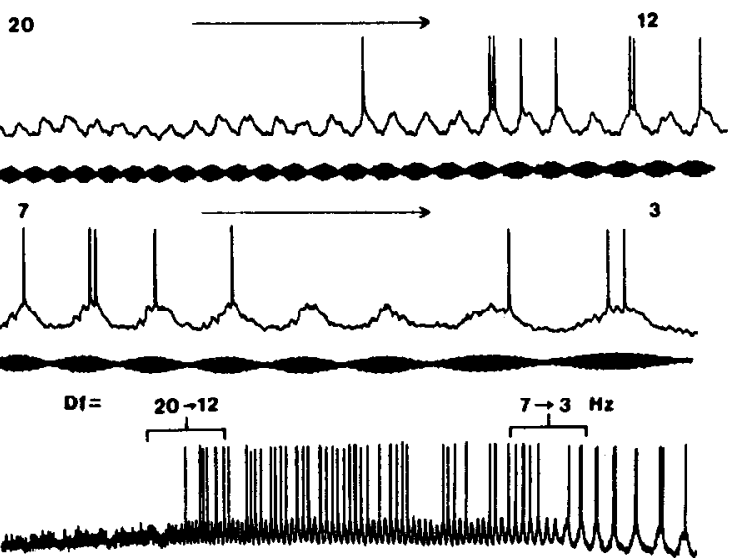

Figure 4. A, Bilaminar neuron of lamina 4. B, Relative amplitude of PSPs evoked by various beat rates (solid symbols) or to 5 , 10 , or $20 \mathrm{~Hz}$ sinusoidal signals (open symbols) delivered through the mouth-tail electrodes (S1). Data taken from the neuron shown in $A$, an E-unit, are represented by circles; the other neuron was an I-unit. $C$, Subthreshold PSPs of neuron shown in $A$ in response to sinusoidal signals of 5 , 10 , and $20 \mathrm{~Hz}$, delivered through mouth-tail electrodes (S1). The top three intracellular traces are time expansions of portions of the bottom intracellular trace. $D$, Intracellular recordings at a slightly more depolarized level than in $C$. Stimuli were beats resulting from addition of two sinusoidal signals and presented through the mouth-tail pair of electrodes.

is, band-pass temporal selectivity (Fig. $4 B$, solid circles). Similarly, the unit showed a band-pass response to the low-frequency stimuli (Fig. $4 B$, open circles). Another bilaminar unit showed band-pass properties to beat stimuli but was nonselective to low-frequency stimuli (Fig. $4 B$, solid and open triangles, respectively).

A third neuron type that, in some cases, exhibited densely spined dendrites is the pyramidal neuron of lamina $8 \mathrm{c}$ (Fig. $5 \mathrm{~A}$ ). These spiny pyramidal neurons showed low-pass properties (Fig. $5 B$ ). For spiny cells, the amplitude envelope of the stimulus was reflected with high fidelity in the low-frequency fluctuations of their membrane potential (Fig. 5C).

Neurons of intermediate spine density. The pyramidal neurons of laminae 4 and 5 were most frequently found to exhibit intermediate densities of dendritic spines. These neurons, however, were rather heterogeneous in morphology and function. It is unclear whether "classes" of pyramidal neurons exist, or if there is a continuum with respect to temporal selectivities and cell morphology. Two moderately spined pyramidal neurons are shown in Figure $6 \mathrm{~A}$. For the lower neuron, the amplitude of stimulus-related PSPs increased slightly as the beat rate was increased (Fig. $6 C$, circles in $B$ ). This neuron was less densely spined than the others in this class. Stable intracellular recordings obtained from two other pyramidal neurons showed weak to moderate low-pass temporal selectivities (Fig. 6B).

Sparsely spined or aspiny neurons. Type c neurons of lamina 5 represent the other end of the spectrum with respect to their anatomy and physiology. The dendrites of these cells were virtually devoid of spines (Fig. $7 A, C$ ). Unlike the type b neurons, these cells poorly coded the amplitude envelope of the beating waveform in the fluctuations of their membrane potential (Fig. 7D). The amplitude of stimulus-related potentials increased with bcat ratc (Fig. $7 B$ ). Particularly at low beat rates, individual PSPs with fast rise and fall times (the entire PSPs lasting less 

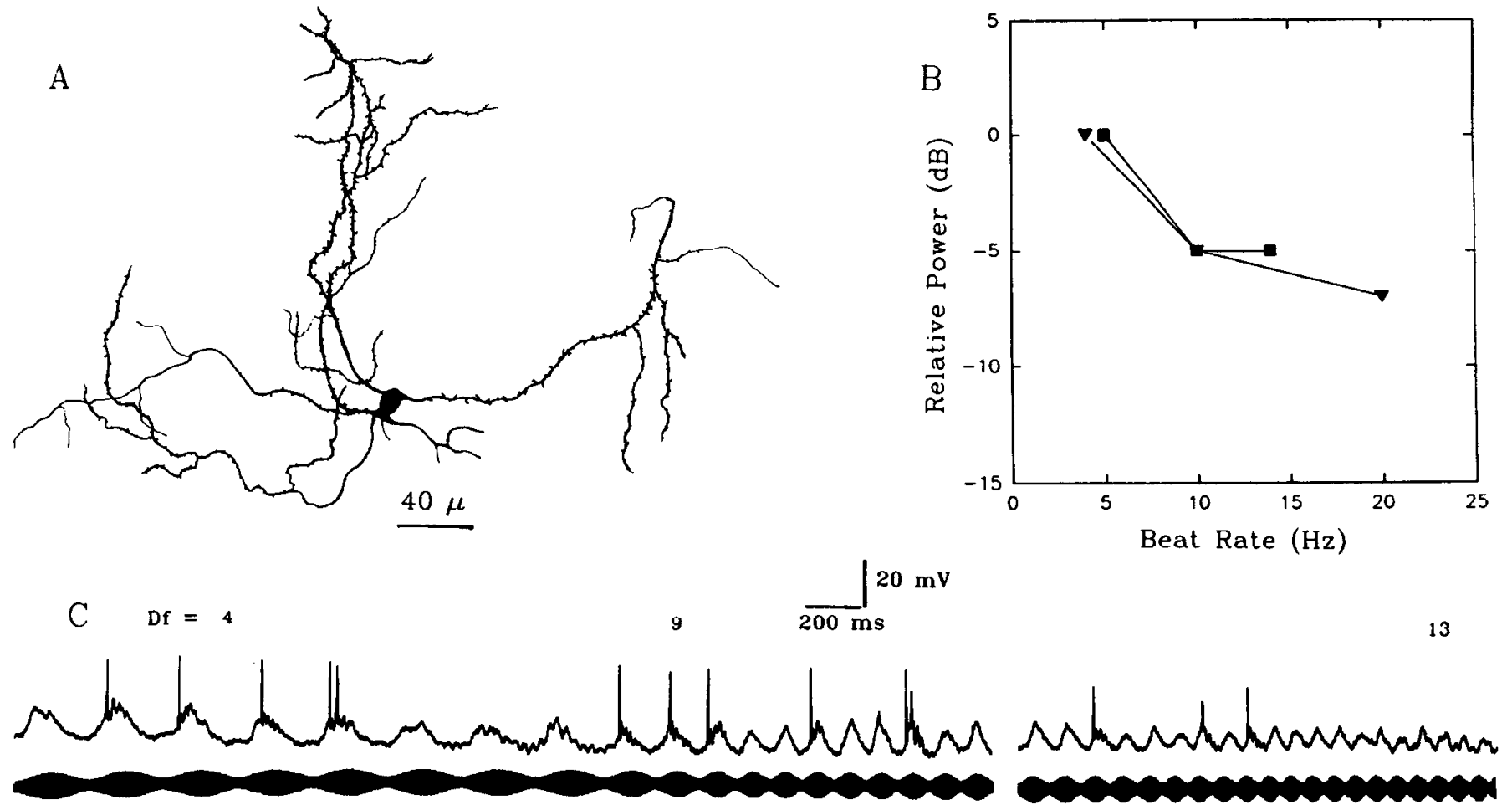

Figure 5. $A$, Pyramidal neuron of lamina 8c. $B$, Relative amplitude of PSPs versus stimulus beat rate for two spiny pyramidal neurons, both E-units. Squares represent data from the neuron shown in $A$. $C$, Intracellular voltage traces for neuron shown in $A$. Recordings were notch filtered at $60 \mathrm{~Hz}$. Variations in the beat rate are described above traces.
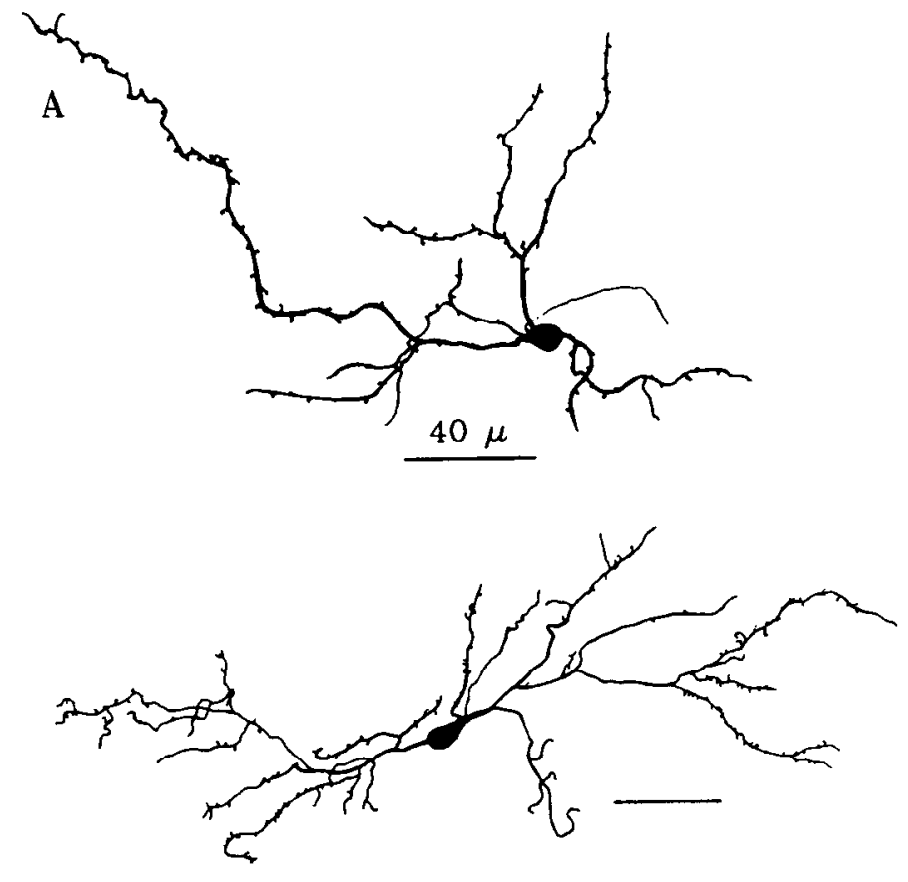

C

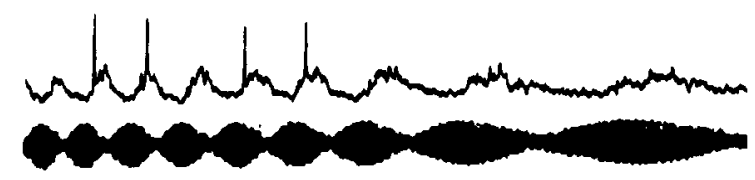

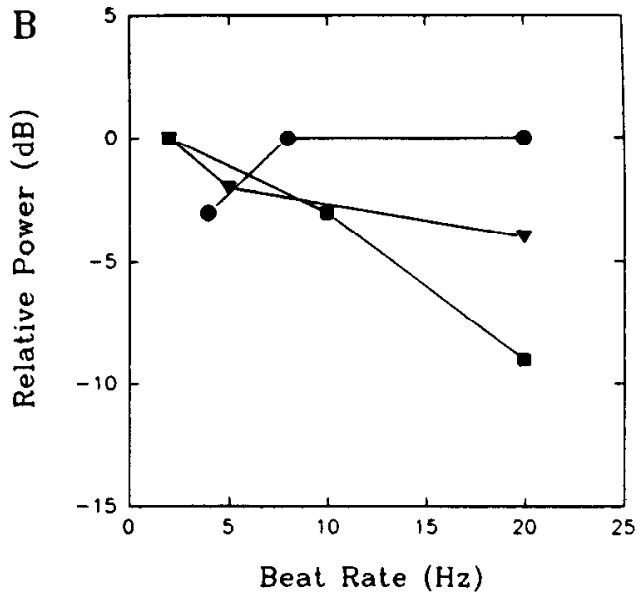

$\overbrace{200 \mathrm{~ms}} 10 \mathrm{mV}$

$\mathrm{Df}=13 \mathrm{~Hz} \rightarrow 20 \mathrm{~Hz}$

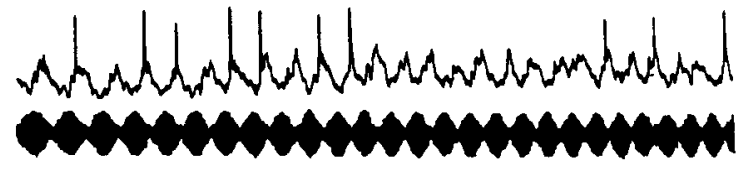

Figure 6. A, Pyramidal/multipolar neurons of lamina 5 (top) and lamina 4 (bottom). $B$, As in previous figures. Circles represent data from neuron in $A$, bottom. All were I-units. $C$, Intracellular recordings from the neuron shown in $A$, bottom. Variations in the beat rate are described above each trace. 


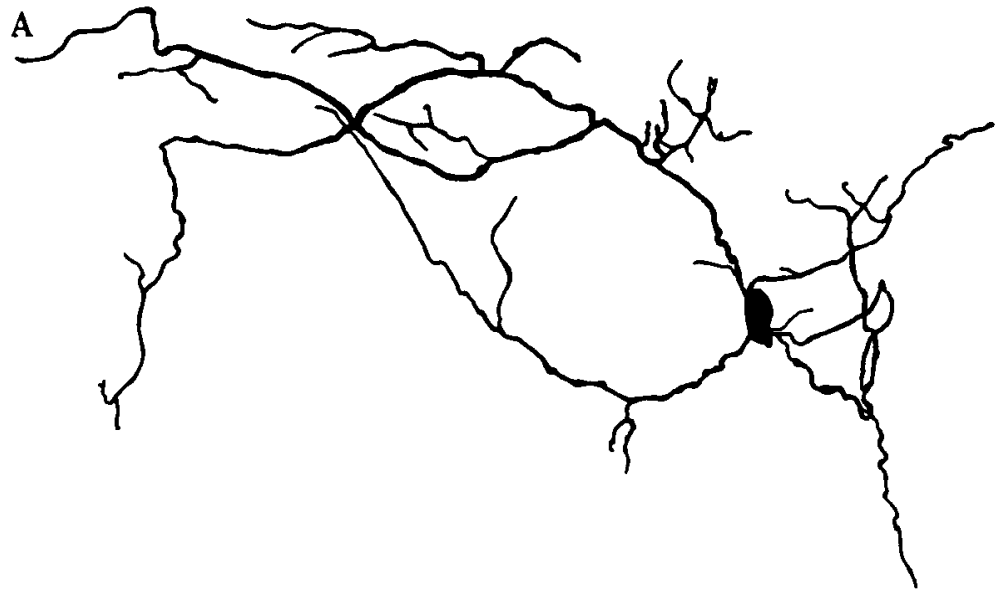

C

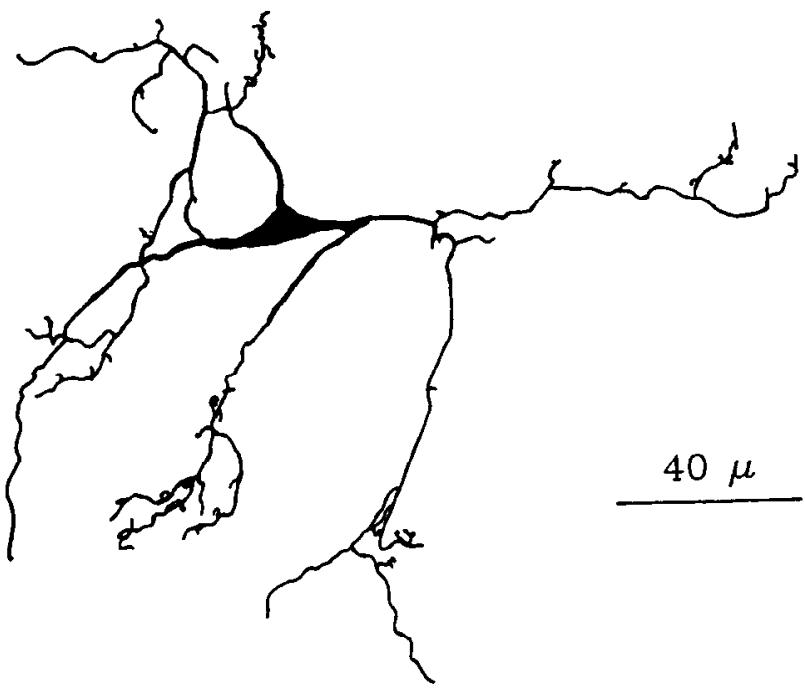

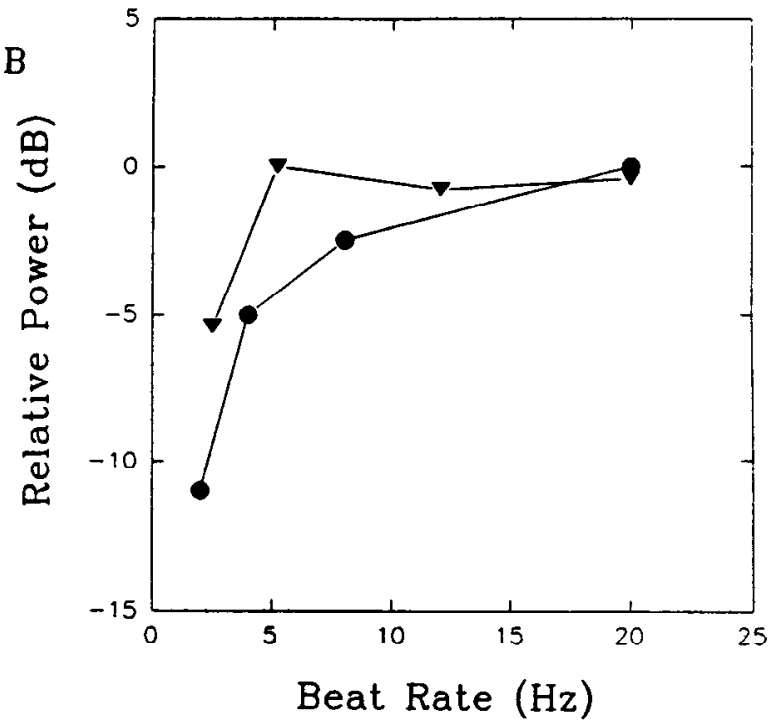

$\mathrm{D}$

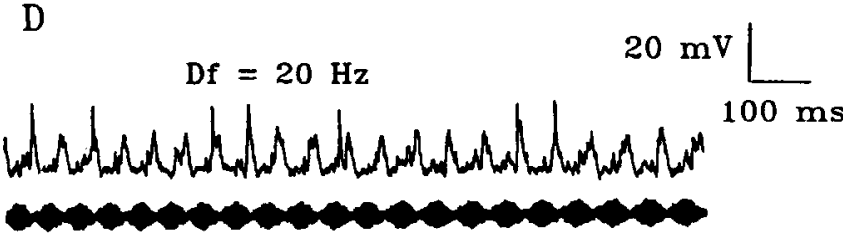

$10 \mathrm{~Hz}$

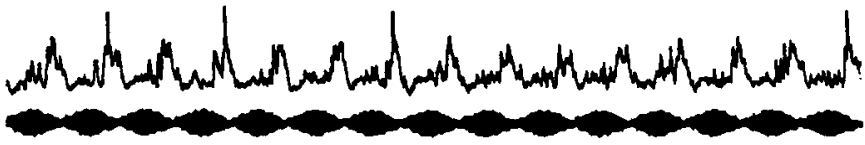

$2 \mathrm{~Hz}$

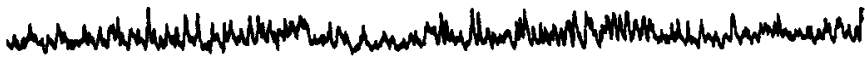

Figure 7. $A$ and $C$, Type c neurons of lamina 5. B, As in previous figures. Circles, data from neuron in $A$; triangles, data from neuron in $C$; both were I-units. $D$, Intracellular voltage traces for neuron in $A$ in response to three different beat rates.

than $5 \mathrm{msec}$ ) were observed. Fast PSPs of this nature also were observed during periods where only the EOD-mimic was present, probably reflecting the spontaneous activity of afferents from the ELL.

In lamina 8c, two multipolar neurons were labeled that had aspiny dendrites and ovoid somas. Both cells were labeled well, yet no spines could be seen. This cell type has not been observed in Golgi material. The amplitude of stimulus-related PSPs of the multipolar neuron shown in Figure 8 was similar over the range of beat rates tested. Stimulus-related fluctuations in the membrane potential of the aspiny neuron had large, high-frequency components (Fig. 8, lower traces), possibly reflecting in some cases individual inputs.

Two neurons in the stratum album centrale of the tectum were labeled that responded to the beating signal (Fig. 9A,C). The dendrites were aspinous and extended primarily horizontally. Intracellular recordings revealed PSPs with fast rise and fall times, that is, high-frequency components, that were most numerous during rises in the amplitude of the stimulus (Fig. $9 D$, data from neuron in $C$ ). The density of these fast PSPs was greatest at the low beat rates and declined precipitously as the beat rate was increased. Fluctuations of the membrane potential best mirrored the amplitude envelope of the stimulus at low beat rates; however, the fidelity of this coding was poor. The relative power in these recordings, at the frequency equal to the beat rate, decreased, therefore, as the beat rate was increased (Fig. 9B).

Summary-spine density and physiology. The mean spine densities of the various neuron types recorded are shown in Figure 10. The octopus, pyramidal, and bilaminar neurons of lamina 4 cannot, at this time, be differentiated on the basis of mean spine density.

In contrast, the three neuron types of lamina 5 differed greatly in mean spine density. Type $c$ neurons were virtually devoid of spines, while type b cells were the most heavily spined of the toral cells recorded. Pyramidal neurons (type a) had spine densities that were intermediate between the other two cell types, and were similar to the pyramidal neurons of lamina 4 .

The relations between the mean spine density of neurons and their temporal filtering properties are summarized in Figure 11. 

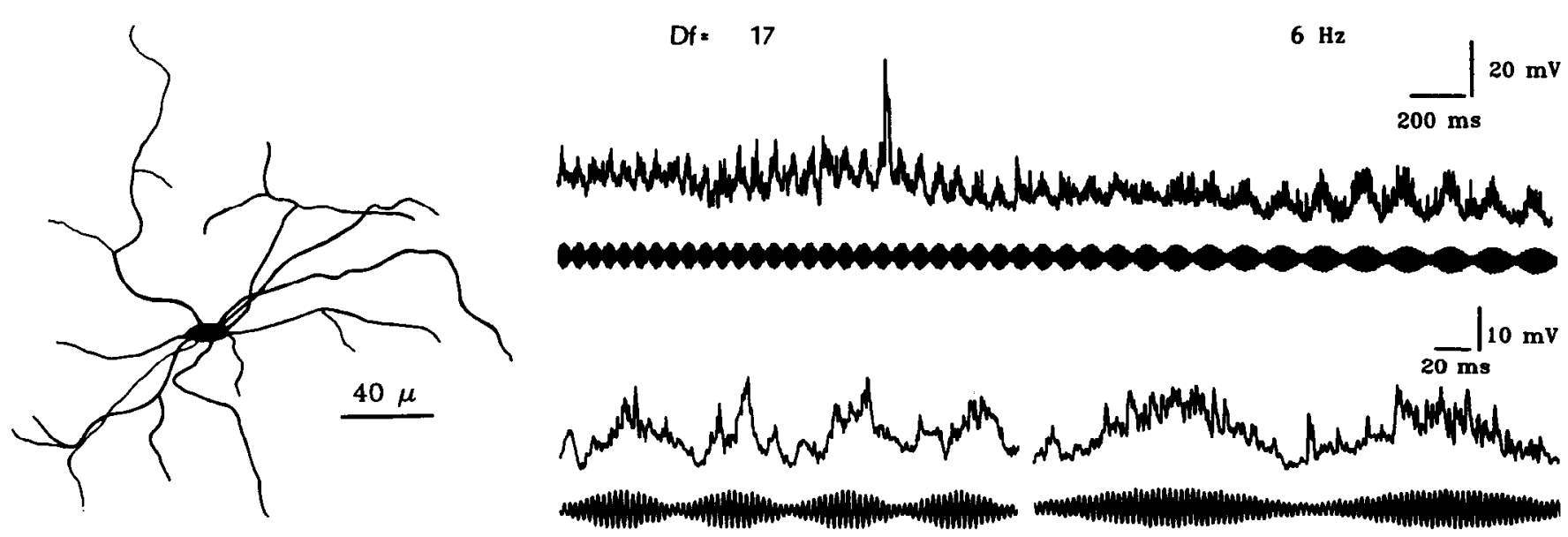

Figure 8. Smooth multipolar neuron of lamina 8c. Intracellular recordings from this neuron are shown at right. Lower traces are time expansions of sections of the upper trace. Note different time and voltage scales. This cell was an E-unit.

The temporal filtering properties of each neuron were quantified by determining the maximum slope ( $\mathrm{dB} /$ octave) of the PSP amplitude (power) versus beat rate curves; positive values reflected low-pass properties. Data from different neuron types are represented by different symbols (as in Fig. 10). As described above, the bilaminar (type b) cells of lamina 5 consistently were heavily spined and showed the strongest low-pass temporal filtering. Aspiny or sparsely spined neurons generally showed little
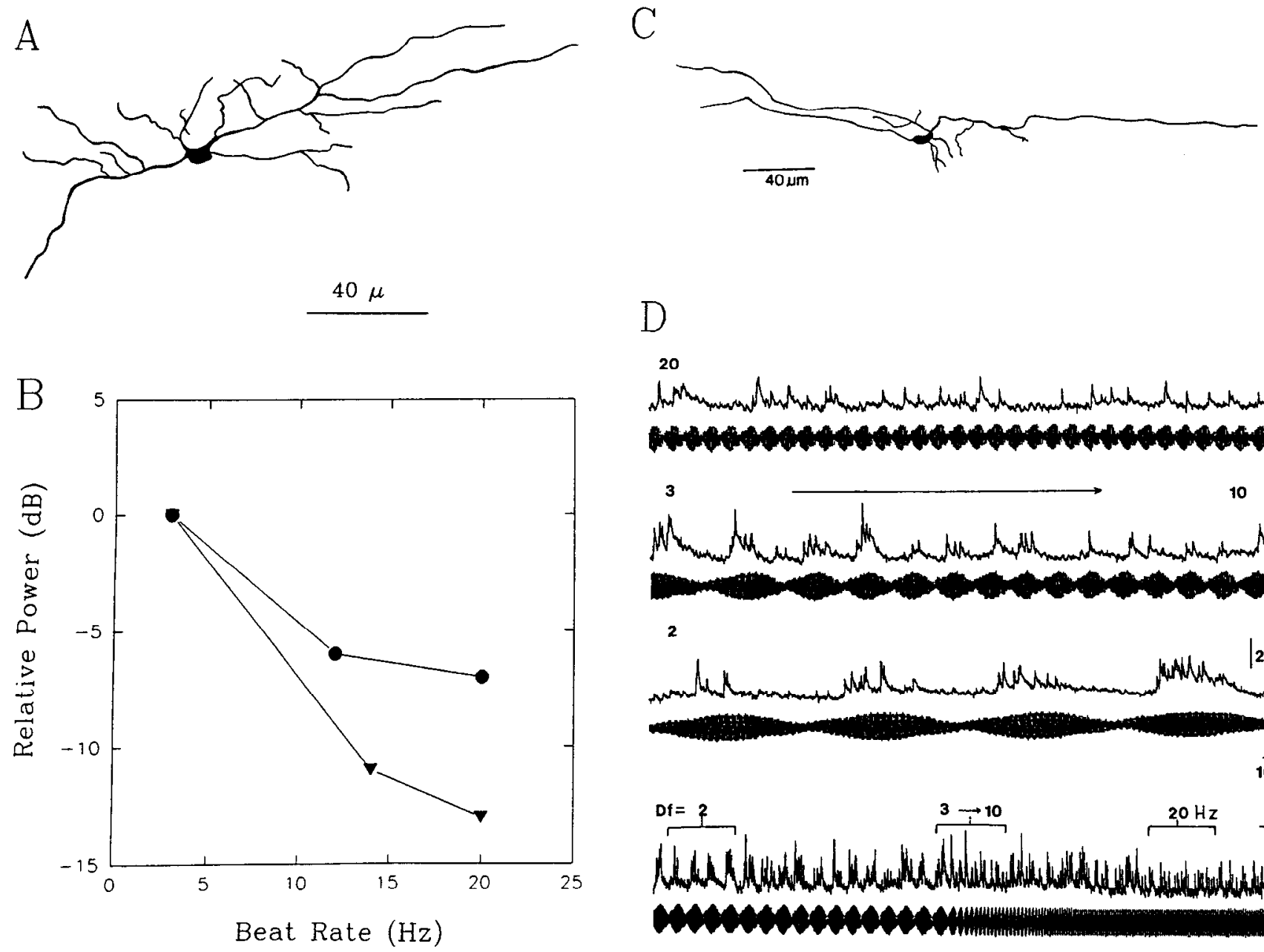

$D$

20

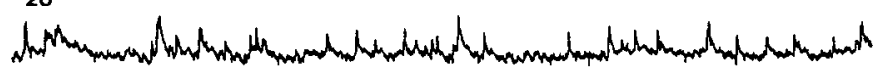

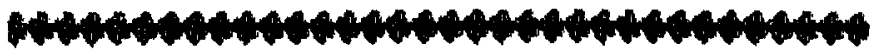

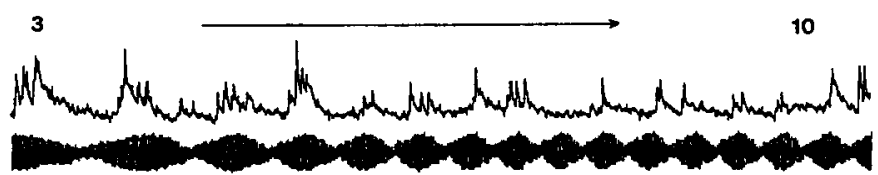

2
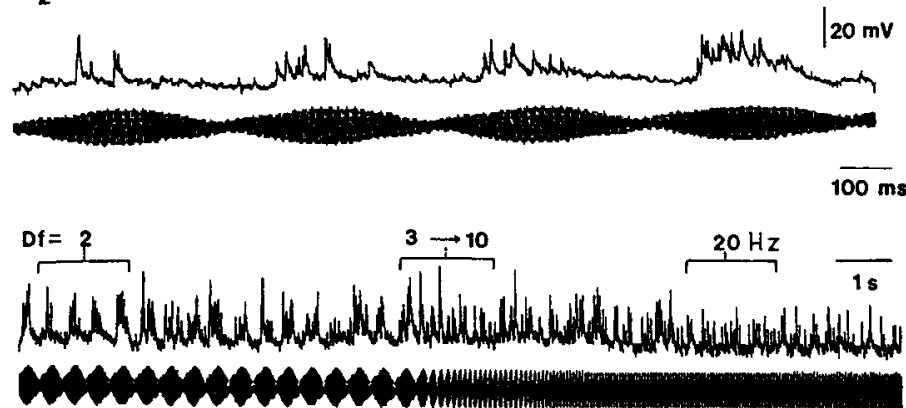

Figure 9. $A$ and $C$, Neurons of the stratum album centrale of the optic tectum that were excited by beats. This layer of the tectum is bounded ventrally by the periventricular zone (stratum periventriculare) and dorsally by the stratum griseum centrale. $B$, Relative PSP amplitude versus beat rate for the neuron in $A$ (circles) and $C$ (triangles). Both cells were E-units. $D$, Intracellular recordings from neuron in $C$. The $t o p$ three pairs of voltage traces are time expansions of the bottom pair. 


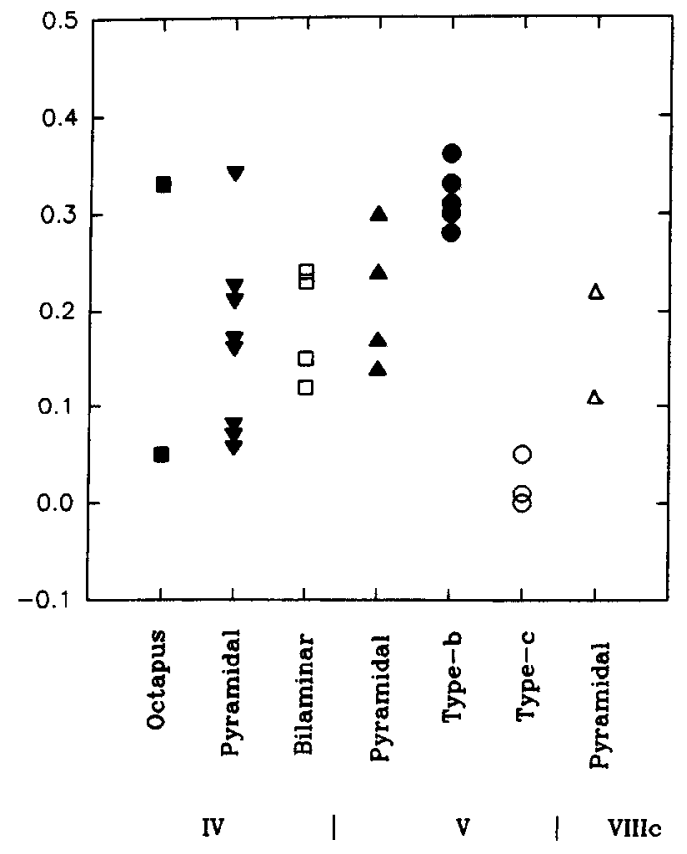

Figure 10. Summary of the spine density measures for the various types of toral neurons labeled in this study. Spine density calculations were made by dividing the total number of spines on a cell by the total dendritic length.

or no low-pass tendencies, with the exception of those in the tectum. The poor responses of tectal neurons to the higher beat rates would be expected if their afferents are low-pass cells.

\section{Discussion}

\section{Mechanisms of temporal filtering}

Two potential mechanisms of temporal filtering were considered, a "delay-line" network model and an electrical filtering mechanism. The delay-line model would involve an excitatory input to toral neurons and a delayed, inhibitory input. The tectum could potentially represent the source of delayed, inhibitory feedback to low-pass and band-pass toral neurons. Con- sider, for example, a delay of $125 \mathrm{msec}$ for the inhibitory feedback. The cell that receives this negative feedback would respond well to a $4 \mathrm{~Hz}$ beat stimulus, since the inhibition would occur during the portion of the beat cycle when excitatory input is lowest, that is, one-half of a beat cycle out of phase with the excitation. As the beat rate is increased, overlap between the excitation and inhibition would increase, and the response of the neuron would decline. A response minimum should occur at a beat rate of $8 \mathrm{~Hz}$, since the $125 \mathrm{msec}$ delay places the inhibition in maximal temporal overlap with the excitation. According to the delay-line model, therefore, response minima should occur at multiples of the preferred beat rate. Since such minima were not observed, this mechanism is not supported.

Alternatively, the decline of PSP amplitude with beat rate may result from an electrical filtering mechanism. The acquisition of synaptic input through dendritic spines might provide such a mechanism. Although the function(s) of dendritic spines has remained largely a mystery since their discovery approximately 100 years ago (Ramon y Cajal, 1909), theoreticians are in general agreement that their long, thin necks should impede axial current flow (Koch and Poggio, 1987; Rall and Segev, 1987; Harris and Stevens, 1989). Depolarizations at the soma, in response to synaptic inputs onto spines, should be smallest, therefore, for the longest and smallest-diameter spines, assuming passive membrane properties of the spine. The potentially high input impedance of spines is likely to influence the temporal filtering properties of neurons (Koch and Poggio, 1983). In support of this notion, the heavily spined toral neurons exhibited fluctuations of their membrane potential that closely reflected the amplitude envelope of the beat stimulus. PSPs with fast rise and fall times were not observed. Thus, the afferent coding of amplitude information in the stimulus by the probability of occurrence of spikes had been "read" (Bialek et al., 1991) to recover an analog representation of the beat envelope. The amplitude of these PSPs declined markedly as the beat rate was increased, that is, showed temporal low-pass characteristics. In contrast, aspiny neurons failed to reflect with high fidelity the beat envelope of the stimulus in the fluctuations of their membrane potential. Instead, the amplitude envelope was reflected in the density of PSPs with fast rise and fall times.
Figure 11. Plot of spine density versus temporal filtering properties for toral neurons recorded in this study. Symbols represent the various neuron types, as detailed in Figure 10; the square with an " $X$ " in it represents data taken from a smooth, multipolar neuron of lamina $8 \mathrm{c}$. The two tectal neurons were not included in this presentation. Complete physiological records were not obtained for all of the neurons presented in Figure 10 .

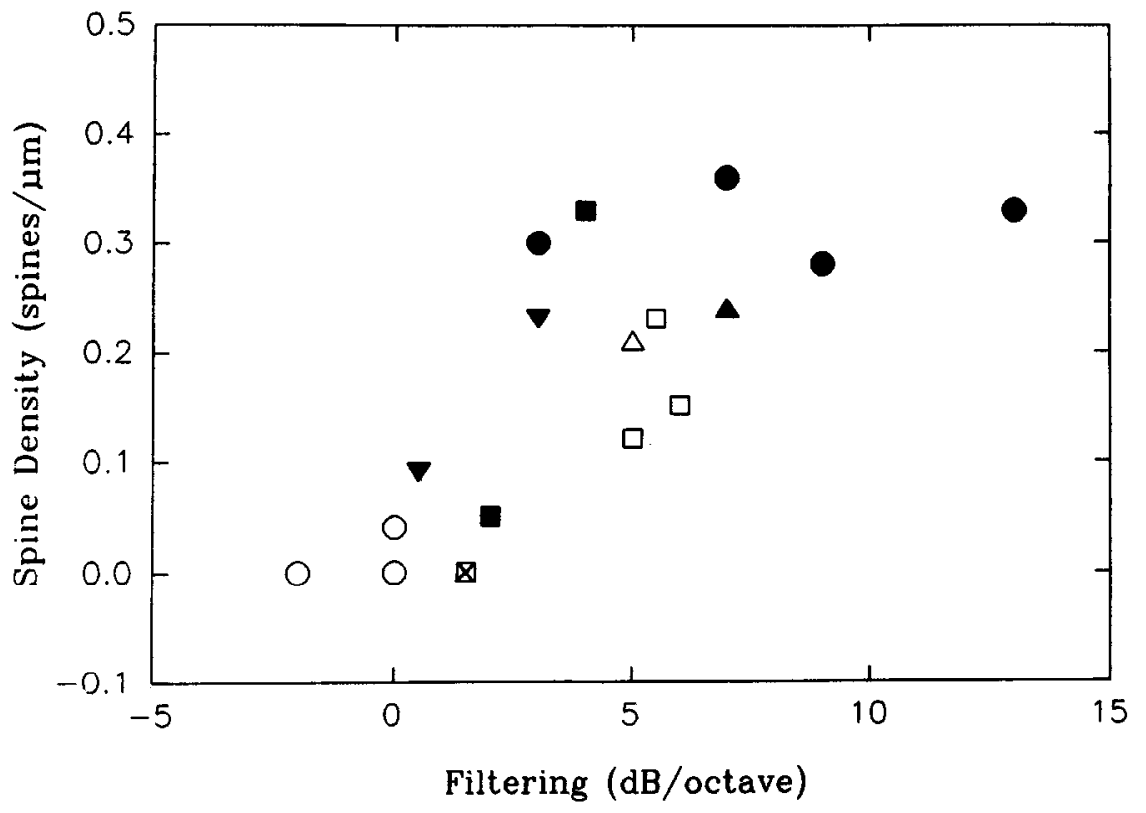


The temporal low-pass characteristics may not be a strict function of the density of dendritic spines for several reasons. First, the dimensions of the spines may differ between cell types; longer, smaller-diameter spines should impart greater temporal filtering. Ultrastructural investigations should permit quantification of these differences. Second, spine-related temporal filtering can only be expected to the extent that afferents synapse onto them versus onto other parts of the cell. For example, a neuron with a comparatively low density of long, thin spines may exhibit strong low-pass temporal filtering if the cell receives all or most of its afferents onto spines.

A third type of mechanism for generating low-pass temporal filtering incorporates voltage and time-dependent conductances of channels in the cell membrane. Such a mechanism would require that some channels open only after maintained depolarization. Sustained transmitter release and, therefore, depolarization of the postsynaptic cell would be greatest at the slowest beat rates. According to this model, depolarizations of the membrane potential of low-pass neurons in response to beat stimuli should have faster rise times and be substantially delayed relative to the amplitude envelope of the stimulus. Instead, however, stimulus-related fluctuations of the membrane potential closely follow, in time and form, the amplitude envelope of the stimulus. While these observations suggest that voltage- and time-dependent conductances probably do not play an important role in generating the low-pass temporal filtering properties of toral neurons, additional tests of this model are needed.

Thus, the evidence reported in this article provides support for the notion that dendritic spines contribute to the low-pass temporal filtering properties of toral neurons. While these data do not support the other theoretically plausible models considered above, they do not exclude the possibility that other types of mechanisms (not yet described) may be operative. Recently there has been a trend away from the viewpoint that spines modulate the electrical properties of cells to the view that they play a role in chemical compartmentalization (Koch et al. 1992). In evaluating this shift in position, several points should be made. First, this change in thinking largely stems from theoretical analyses of neurons that exhibit much shorter spines than observed for toral neurons. Second, these are not mutually exclusive hypotheses. Finally, it is worth remembering that a basic function of spines may be to expand the potential number of inputs to a neuron. It is probably imprudent at this point to expect that dendritic spines will have a single functional role.

The increase in response of some neurons as the beat rate was increased is probably attributable to the recurrent inhibition from the nucleus praeeminentialis to the ELL via the cerebellum (Bastian, 1986b,c). This negative feedback contributes to the response adaptation of ELL neurons. Mean time constants of adaptation range from $30 \mathrm{msec}$, for the lateral map, to $74 \mathrm{msec}$ for the centromedial map, with a great deal of overlap in this property between maps (Shumway, 1989). As expected, shorter time constants of adaptation are associated with more pronounced high-pass response properties for beat stimuli.

\section{Functional differentiation of cell types}

The diversity of neuron types in the torus has raised the question of how morphological differences might be related to function. Structure-function relations have been clearest in lamina 6, where the giant cells and small cells are specialized for coding phase and phase differences, respectively (Heiligenberg and Rose, 1985; Carr et al., 1986). In general, however, functional correlates of inter- and intralaminar heterogeneity in cell structure have been lacking. The present study shows that the type $b$ (heavily spined) and type c (virtually aspinous) neurons of lamina 5 respond in a low-pass and high-pass (or nonselective) fashion, respectively, to beat rates in the range of 2-20 Hz. Further, type b neurons show smooth, slow PSPs that nicely reflect the amplitude envelope of the stimulus, whereas type cells code this information primarily in the temporal density of fast PSPs. The pyramidal neurons (type a) of lamina 5 are of intermediate spine density and temporal filtering properties.

Lamina $8 \mathrm{c}$ has spiny pyramidal neurons and large, previously unreported, aspiny multipolar neurons. As in lamina 5, the spiny neurons of $8 \mathrm{c}$ showed stimulus-related fluctuations of their membrane potential that reflected the amplitude envelope of the stimulus with high fidelity. The amplitude of these potentials declined with higher beat rates. Aspiny neurons, however, showed fast PSPs, and coded the amplitude of beat stimuli with low fidelity. The amplitude of these stimulus-related PSPs declined only slightly as the beat rate was increased. Lamina $8 \mathrm{c}$ receives afferent input from the ELL (Fig. 1) and from neurons of lamina 5 (Rose and Heiligenberg, 1985). If aspiny neurons of lamina $8 \mathrm{c}$ receive excitatory inputs from spiny cells of lamina 5 , then the strength of their response should diminish as the beat rate is increased. Alternatively, the aspiny and spiny neurons of $8 \mathrm{c}$ may be connected principally to their counterparts in lamina 5 . Such connectivity would constitute local, parallel circuits for fast and slow temporal information.

Tectal neurons of the stratum album centrale had aspiny dendrites and, like aspiny toral cells, coded the amplitude envelope of beat stimuli in their temporal density of fast PSPs. Unlike aspiny toral neurons, however, these cells responded less vigorously as the beat rate was increased. These data suggest that the tectal neurons recorded receive input from temporal lowpass neurons of the torus. This notion is supported by the finding that type $b$ (low-pass), but not type $c$ (high-pass/nonselective), neurons of lamina 5 project to the tectum (Carr et al., 1981). The periventricular neurons appear to be the only other tectal cell type that respond to beat stimuli (Heiligenberg and Rose, 1987).

The bilaminar neurons of lamina 4 extend their apical dendrites into lamina 3 , and their basal dendrites into lamina 5 . As described in a previous study (Rose and Call, 1992), these neurons receive input from the ampullary and tuberous systems. The integration of ampullary and tuberous information also occurs in neurons located in laminae below 6 (Metzner and Heiligenberg, 1991).

Role of temporal filter neurons in the generation and evolution of the jamming avoidance response

Eigenmannia produces largest JARs for beat rates of approximately 3-8 Hz (Bullock et al., 1972; Heiligenberg et al., 1978; Partridge et al., 1981; Bastian and Yuthas, 1984). Only rarely do fish show maximal responses for beat rates outside this range (Rose et al., 1988). Why should the strength of the behavior diminish as the absolute magnitude of the frequency difference between a fish's EOD and that of a jamming signal (Df) exceeds approximately $8 \mathrm{~Hz}$ ? Would it not be functionally advantageous for the fish swiftly to change its EOD frequency until the minimum jamming condition was realized? Instead, the strength of the behavior starts to decrease at Df values that are only slightly greater than those that maximally jam the fish's electrolocation abilities (Matsubara and Heiligenberg, 1978). 
This lack of optimality could be a consequence of the utilization of extant neural circuits for the evolution of this behavior (Dumont and Robertson, 1986). Support for the idea that electrolocation and jamming avoidance behaviors share much of the same neural circuitry comes from the demonstration that small shifts of the EOD frequency can be induced by the motion of objects alongside the fish's head (Rose and Heiligenberg, 1986). Such stimuli create temporal patterns of modulation of signal amplitude and differential phase similar to those that elicit JARs. It seems likely that the neural mechanisms of temporal filtering predated the evolution of the JAR, since without it the behavior would be of little use. Specifically, the rejection of high modulation rates, that is, low-pass temporal filtering, by toral neurons permits the detection of slow, object-induced modulations in the presence of fast, jamming-related modulations (Matsubara and Heiligenberg, 1978; Bastian, 1987). In support of this idea, Sternopygus, a gymnotiform electric fish that is closely related to Eigenmannia (Mago-Leccia, 1978), possesses modulation filters (Rose et al., 1987; Rose and Canfield, 1991), yet does not have a JAR (Bullock et al,, 1972). These filters, therefore, may have predated the evolution of the JAR, permitting information concerning slow modulations of signal amplitude to be extracted while rejecting that of faster modulations; modulation filters may have constituted the "first" jamming avoidance mechanism. If, in the evolution of its JAR, Eigenmannia utilized this extant population of temporal filter neurons, then the observed dependency of the strength of the behavior on beat rate would result.

\section{Comparisons with other systems}

The same classes of temporal selectivities seen for toral neurons to beat rates (low-pass, band-pass, high-pass) have been observed for neurons in the central auditory systems of crickets (Schildberger, 1984) and anurans (Rose and Capranica, 1983, 1985; Walkowiak, 1984) in response to amplitude-modulated sounds. Band-pass neurons show tuning to modulation rates found in the species-specific communication sounds (Rose and Capranica, 1984; Rose et al., 1985). Foster et al. (1985) have recorded visual neurons in cortical areas $\mathrm{V} 1$ and $\mathrm{V} 2$ that showed low-pass and band-pass temporal selectivities in response to periodic motion of a sinewave grating. Interestingly, band-pass neurons in visual cortex are tuned to temporal frequencies of 2-6 Hz, precisely the range of beat rates to which most toral neurons are tuned. Further, similar to electrosensory cells in the torus, most temporally selective neurons in visual cortex show at least a $50 \%$ decline in response rate for temporal frequencies above approximately $12 \mathrm{~Hz}$. Such evidence raises the possibility that similar mechanisms might underlie temporal filtering in the electrosensory and visual systems.

The PSPs of spiny toral neurons reflected with high fidelity the amplitude envelope of the beat stimulus, whereas aspiny neurons coded this information with low fidclity. Similarly, following cerebellar stimulation in cats, slow, smoothly rising EPSPs are recorded in spiny pyramidal neurons of motor cortex, whereas fast EPSPs are recorded in aspiny stellate cells (Noda and Yamamoto, 1984). Upon peripheral nerve stimulation, neurons in somatosensory cortex with heavily spined apical dendrites exhibit slow, smoothly rising EPSPs whereas those with aspiny apical dendrites have fast rising EPSPs (Yamamoto et al., 1987). Wilson et al. (1990), recording intracellularly in the neostriatum of rats, found that unitary synaptic potentials (EPSPs) in aspiny interneurons were of large amplitude and fast time course. Po- tentials resulting from the activity at individual synapses on spiny neurons, in contrast, were not large enough to be detected in these intracellular recordings. In response to afferent stimulation, PSPs of spiny neurons appear, therefore, to reflect the correlated and sustained activity of many inputs.

Thus, the acquisition of synaptic input through dendritic spines may be a general mechanism for selecting slowly varying, general trends in the afferent input to a cell and filtering out transient information.

\section{References}

Bastian J (1981a) Electrolocation. I. How the electroreceptors of Apteronotus albifrons code for moving objects and other electrical stimuli. J Comp Physiol 144:465-479.

Bastian J (1981b) Elcctrolocation. II. The effects of moving objects and other electrical stimuli on the activities of two categories of posterior lateral line lobe cells in Apteronotus albifrons. J Comp Physiol 144:481-494.

Bastian J (1986a) Electrolocation: behavior, anatomy and physiology. In: Electroreception (Bullock TH, Heiligenberg W, eds), pp 577-612. New York: Wiley.

Bastian J (1986b) Gain control in the electrosensory system mediated by descending inputs to the electrosensory lateral line lobe. J Neurosci 6:553-562.

Bastian J (1986c) Gain control in the electrosensory system: a role for the descending projections to the electrosensory lateral line lobe. $J$ Comp Physiol 158:505-515.

Bastian J (1987) Electrolocation in the presence of jamming signals: behavior. J Comp Physiol 161:811-824.

Bastian J, Yuthas J (1984) The jamming avoidance response of $E i$ genmannia: properties of a diencephalic link between sensory processing and motor output. J Comp Physiol [A] 154:895-908.

Bennett MVL (1971) Electric organs. In: Fish physiology (Hoar WS, Randall DJ, eds), pp 493-574. New York: Academic.

Bialek W, Rieke F, De Ruyter van Steveninck RR, Warland D (1991) Reading a neural code. Science 252:1854-1856.

Bullock TH (1982) Electroreception. Annu Rev Neurosci 5:121-170. Bullock TH, Hamstra RH, Scheich H (1972) The jamming avoidance response of high-frequency electric fish. J Comp Physiol 77:1-48.

Carr CE, Maler L (1985) A Golgi study of the cell types of the dorsal torus semicircularis of the electric fish Eigenmannia: functional and morphological diversity in the midbrain. J Comp Neurol 235:207240 .

Carr CE, Maler L (1986) Electroreception in gymnotiform fish: central anatomy and physiology. In: Electroreception (Bullock TH, Heiligenberg W, eds), pp 319-374. New York: Wiley.

Carr CE, Maler L, Heiligenberg W, Sas E (1981) Laminar organization of the afferent and efferent systems of the torus semicircularis of gymnotiform fish: morphological substrates for parallel processing in the electrosensory system. J Comp Neurol 203:649-670.

Carr CE, Maler L, Sas E (1982) Peripheral organization and central projections of the electrosensory nerves in gymnotiform fish. J Comp Neurol 211:139-153.

Carr CE, Maler L, Taylor B (1986) A time comparison circuit in the electric fish midbrain. II. Functional morphology. J Neurosci 6:13721383.

Dumont PC, Robertson RM (1986) Neuronal circuits: an evolutionary perspective. Science 233:849-853.

Foster KH, Gaska JP, Nagler M, Pollen DA (1985) Spatial and temporal frequency selectivity of neurones in visual cortical area V1 and $\mathrm{V} 2$ of the macaque monkey. J Physiol (Lond) 365:331-363.

Giloh H, Sedat JW (1982) Fluorescence microscopy: reduced photobleaching of rhodamine and fluorescein protein conjugates by n-propyl gallate. Science 217:1252-1255.

Harris KM, Stevens IK (1989) Dendritic spines of CAl pyramidal cells in the rat hippocampus: serial electron microscopy with reference to their biophysical characteristics. J Neurosci 9:2982-2997.

Heiligenberg W (1973) Electrolocation of objects in the electric fish Eigenmannia (Rhamphichthyidae, Gymnotoidei). J Comp Physiol 87:137-164.

Heiligenberg W (1989) Central processing of electrosensory information in gymnotiform fish. J Exp Biol 146:255-275. 
Heiligenberg W (1991) Neural nets in electric fish. Cambridge, MA: MIT Press.

Heiligenberg W, Dye JC (1982) Labelling of electroreceptive afferents in gymnotoid fish by intracellular injection of HRP: the mystery of multiple maps. J Comp Physiol [A] 148:287-296.

Heiligenberg W, Rose GJ (1985) Phase and amplitude computations in the midbrain of an electric fish: intracellular studies of neurons participating in the jamming avoidance response of Eigenmannia. J Neurosci 2:515-531.

Heiligenberg W, Rose G (1987) The optic tectum of the gymnotiform electric fish Eigenmannia: labelling of physiologically identified cells. Neuroscience 22:331-340.

Heiligenberg W, Baker C, Matsubara J (1978) The jamming avoidance response in Eigenmannia revisited: the structure of a neuronal democracy. J Comp Physiol 127:267-286.

Hose B, Langner G (1988) Separate coding of high and low temporal envelope frequencies in the auditory forebrain of the mynah bird. Soc Neurosci Abstr 14:133.6.

Koch C, Poggio T (1983) A theoretical analysis of electrical properties of spines. Proc R Soc Lond [Biol] 218:455-477.

Koch C, Poggio T (1987) Biophysics of computation: neurons, synapses and membranes. In: Synaptic function (Edelman GM, Gall GE, Cowan WM, eds), pp 637-697. New York: Wiley.

Koch C, Zador A, Brown TH (1992) Dendritic spines: convergence of theory and experiment. Science 256:973-974.

Mago-Leccia F (1978) Los peces de la familia Sternopygidae de Venezuela. Acta Scient Venezolana 29[Suppl 1]:1-89.

Maler L (1979) The posterior lateral line lobe of certain gymnotoid fish: quantitative light microscopy. J Comp Neurol 183:323-364.

Maler L, Sas E, Rogers J (1981) The cytology of the posterior lateral line lobe of high frequency weakly electric fish (Gymnotidae): dendritic differentiation and synaptic specificity in a simple cortex. $J$ Comp Neurol 195:87-141.

Maler L, Sas E, Carr CE, Matsubara J (1982) Efferent projections of the posterior lateral line lobe in gymnotiform fish. J Comp Neurol 211:154-164.

Matsubara J, Heiligenberg W (1978) How well do electric fish electrolocate under jamming? J Comp Physiol 149:339-351.

Metzner W, Heiligenberg W (1991) The coding of signals in the electric communication of the gymnotiform fish Eigenmannia: from electroreceptors to neurons in the torus semicircularis of the midbrain. J Comp Physiol 169:135-150.

Noda T, Yamamoto T (1984) Response properties and morphological identification of neurons in the cat motor cortex. Brain Res 306:197206.

Partridge BL, Heiligenberg W, Matsubara J (1981) The neural basis for a sensory filter in the jamming avoidance response: no grandmother cells in sight. J Comp Physiol 145:153-168.

Peters A, Kaiserman-Abramof IR (1970) The small pyramidal neuron of the rat cerebral cortex. The perikaryon, dendrites and spines. Am J Anat 127:321-356.

Peters A, Palay SI, Webster HD (1991) The fine structure of the nervous system, pp 82-96. New York: Oxford UP.

Rall W, Segev I (1987) Functional possibilities for synapses on dendrites and dendritic spines. In: Synaptic function (Edelman GM, Gall WE, Cowan WM, eds), pp 605-636. New York: Wiley.

Ramon y Cajal S (1909) Histologie du systeme nerveux de l'homme et des vertebres, Vol 1. Paris: Maloine. Reprint. Madrid: Consejo Superior de Investigaciones Cientificas, 1952.
Rose GJ (1986) A temporal processing mechanism for all species? Brain Bchav Evol 28:134-144.

Rose GJ, Call SJ (1992) Differential distribution of ampullary and tuberous processing in the torus semicircularis of Eigenmannia. $J$ Comp Physiol 170:253-261.

Rose GJ, Canfield JG (1991) Discrimination of the sign of frequency differences by Sternopygus, an electric fish without a jamming avoidance response. J Comp Physiol 168:461-467.

Rose GJ, Capranica RR (1983) Temporal processing in the central auditory system of the leopard frog (Rana pipiens). Science 219:10871089.

Rose GJ, Capranica RR (1984) Processing amplitude-modulated sounds by the auditory midbrain of two species of toads: matched temporal filters. J Comp Physiol 154:211-219.

Rose GJ, Capranica RR (1985) Sensitivity to amplitude modulated sounds in the anuran auditory system. J Neurophysiol 53:446-465.

Rose GJ, Heiligenberg W (1985) Processing phase and amplitude information by the midbrain of an electric fish: relationship between structure and function. J Neurosci 5:2269-2280.

Rose GJ, Heiligenberg W (1986) Neural coding of difference frequencies in the midbrain of the electric fish Eigenmannia: reading the sense of rotation in an amplitude-phase plane. J Comp Physiol [A] 158:613-624

Rose GJ, Brenowitz EA, Capranica RR (1985) Species specificity and temperature dependency of temporal processing by the auditory midbrain of two species of treefrogs. J Comp Physiol 157:763-769.

Rose G, Keller C, Heiligenberg W (1987) 'Ancestral' neural mechanisms of electrolocation suggest a substrate for the evolution of the jamming avoidance response. J Comp Physiol 160:491-500.

Rose GJ, Kawasaki M, Heiligenberg W (1988) 'Recognition units' at the top of a neuronal hierarchy? J Comp Physiol 162:759-772.

Saunders J, Bastian J (1984) The physiology and morphology of two types of electrosensory neurons in the weakly electric fish Apteronotus leptorhynchus. J Comp Physiol [A] 154:199-209.

Schildberger K (1984) Temporal selectivity of identified auditory neurons in the cricket brain. J Comp Physiol 155:171-186.

Schnitzler HU, Meene D, Rudi K, Heblich K (1984) The acoustical image of fluttering insects in echolocating bats. In: Neuroethology and behavioral physiology. Roots and growing points (Huber F, Markl H, eds), pp 235-250. Berlin: Springer.

Schreiner CE, Urbas JV (1986) Representation of amplitude modulation in the auditory cortex of the cat. I. The anterior auditory field (AAF). Hearing Res 21:227-241.

Schreiner CE, Urbas JV (1988) Representation of amplitude modulation in the auditory cortex of the cat. II. Comparison between cortical fields. Hearing Res 32:49-64.

Shumway CA (1989) Multiple electrosensory maps in the medulla of weakly electric gymnotiform fish. I. Physiological differences. J Neurosci 9:4388-4399.

Walkowiak W (1984) Neuronal correlates of the recognition of pulsed sound signals in the grass frog. J Comp Physiol 155:57-66.

Wilson CI, Chang HT, Kitai ST (1990) Firing patterns and synaptic potentials of identified giant aspiny neurons in the rat neostriatum. J Neurosci 10:508-519.

Yamamoto T, Samejima A, Oka H (1987) Morphology of layer V pyramidal neurons in the cat somatosensory cortex: an intracellular HRP study. Brain Res 437:369-374.

Zakon HH (1986) The electroreceptive periphery. In: Electroreception (Bullock TH, Heiligenberg W, eds), pp 103-156. New York: Wiley. 